\title{
Significance of crude and degummed Citrullus lanatus seed oil on inflammatory cytokines in experimental infection induced by Candida albicans
}

*Victor Onukwube APEHa, Felicia I. CHUKWUMA, Florence Nkechi NWORA, Obioma Uzoma NJOKU, Fred 0. NWODO

a. Department of Biochemistry, University of Nigeria, Nsukka.

\begin{abstract}
This study evaluated immunomodulatory and candidacidal properties of Citrullus lanatus seed oil (CLSO) on Candida albicans-infected rat. The immunomodulatory and candidacidal activities of both crude and degummed oil at varied doses were determined using 80 female albino rats, randomised into 10 groups of 8 rats per group based on the days 7 and 14 of study. Delayed hypersensitivity reaction showed a significant increase $(\mathrm{p}<0.05)$ in the hind paw oedema of rats treated with crude and degummed oil after 24 hours; however after 48 hour, a significant decrease $(p<0.05)$ in hind paw oedema was observed. However, the CD4 + T-lymphocytes decreased at day 14 when compared with day 7 counterpart. In the same vein, IFN- $\gamma$ and TNF- $\alpha$ decreased from day 7 to day 14 of the study; while IL-10 and IgA increased from day 7 to day 14 of the study. CLSO does not boost immune system, rather demonstrated anti-inflammatory activities of the oil.
\end{abstract}

Keywords: Candidiasis; CD4 count; cytokines; degummed oil; immunosuppression.

\section{INTRODUCTION}

Interest in the effects of fatty acids upon the immunity and inflammation dates back many years, but this interest intensified with the elucidation of the roles of eicosanoids derived from arachidonic acid (ARA; 20:4n-6) in modulating immunity and inflammation ${ }^{1}$, and with the knowledge that the metabolism of ARA to yield these mediators can be inhibited by the long polyunsaturated fatty acids (PUFA). ${ }^{1}$ Free fatty acids may modify the immune response by modulating immunological parameters such as phagocytosis or cytokine production. ${ }^{2}$ Dietary

${ }^{\star}$ Corresponding author: Victor Apeh, e-mail: victorapeh@yahoo.com ORCID: https://orcid.org/0000-0003-2987-4046

(Received 11 April 2020, accepted 10 November 2020) 
lipids or free fatty acids not only affect the immune systems directly, but also interfere in the production of other substances through modification of activity of enzymes involved in the synthesis of these substances. ${ }^{3}$ Disorders of the immune system can result in autoimmune diseases, inflammatory diseases and cancer ${ }^{4}$, and immunodeficiency. Immunodeficiency occurs when the immune system is less active than normal, resulting in recurring and life-threatening infections.

The currently available drugs that are used for the treatment of inflammatory and immunodeficiency diseases are often ineffective and require high doses or prolonged periods of treatment, thus causing adverse effects on the gastrointestinal tract, kidneys, and liver. ${ }^{5}$ Thus, the use of natural products or traditional medicines that have favorable therapeutic effects with fewer adverse effects has gained interest in the treatment of immunomodulatory and inflammatory diseases. ${ }^{6}$ Some of the medicinal plants are believed to enhance the natural resistance of the body to infections. ${ }^{7}$

Watermelon (Citrullus lanatus) is taxonomically classified as a member of the Cucurbitaceae family, which is also known as the gourd family. Other gourds include pumpkins, cucumbers, squash, and other melons. It has been investigated for its potential as significant diuretic agents Gul et al. ${ }^{8}$ In addition, the antioxidant activity, total phenolics and flavonoid contents of fermented and unfermented water melon rind (outer layer) have been investigated. ${ }^{9}$ A study has concluded that Citrullus lanatus seed extracts possess antioxidant activity and the potency of antioxidant activity depends on the type of extract. ${ }^{10}$ The $n-$ hexane extract of Citrullus lanatus seed oil has shown a promising role as an anti-inflammatory agent. ${ }^{11}$ There is no documented evidence of immunomodulatory effect of degummed and crude Citrullus lanatus seed oil. As a consequence, experimental oropharyngeal candidiasis infection was induced in rats and treated with both degummed and crude Citrullus lanatus seed oil in order to determine the ability of the oil to modulate of the immune response.

\section{METHODOLOGY}

\section{Materials}

The plant material used in this study was the fresh Citrullus lanatus seeds. The seed of Citrullus lanatus (water melon) was procured from the dealers within Zuba in Bwari area council of FCT Abuja, the identity of the plant was confirmed and Voucher specimens UNN/PSB/Consult/2017/2721-03 were deposited at the herbarium at the Department of Plant Science and Biotechnology, University of Nigeria, Nsukka. 


\section{Fungal strain}

Candida albicans $\mathrm{SC} 5314$ used in this study was obtained from Department of Microbiology University of Nigeria, Nsukka.

\section{Animals and experimental design}

A total of 80 female albino rats weighing 120-150g were obtained from the Animal House of the Faculty of Biological Sciences, University of Nigeria, Nsukka. They were acclimatized for one week under standard environmental conditions and maintained on a regular feed (Grand Cereals Ltd, Enugu, Nigeria) and water ad libitum. The animals were handled according to the guidelines of the Ethical Committee on the use and care of experimental animals of the Department of Biochemistry, University of Nigeria, Nsukka (UNN) and approved by the Departmental Animal Ethics Committee (DAEC), UNN (Approval No. UNN/DAEC/2017/ B79). They were grouped in ten (10) cages of eight (8) rats per cage and orally fed with crude and degummed Citrullus lanatus seed oil (CLSO) for a total of 14 days. Controls were treated with $2 \%$ Tween 80 while fluconazole and levamisol as standard drugs. The rats were sacrificed on the $14^{\text {th }}$ day, blood samples were collected through ocular puncture for biochemical and haematological analyses.

\section{Methods}

\section{Collection and processing of Citrullus lanatus.}

The fruits were washed, cut and the seeds selected manually from the pulp. Tap water was used to wash off pulp on the seeds before sun-drying for 72 hours. Samples of watermelon seeds were crushed using a commercial blender (TSK949, WestPoint, France), put in air tight container and stored in a desiccators for analyses.

\section{Oil extraction and determination of percentage yield}

The pulverized samples weighing $2480 \mathrm{~g}$ were extracted for $6 \mathrm{~h}$ using $\mathrm{n}$-haxane and soxhlet extractor equipped with thimble (chem glass). The extract was then concentrated using rotary evaporator (EYELA, N-N Series; Rikakikai Co Ltd., Tokyo, Japan) to obtain n-hexane-free crude Citrullus lanatus seed oil. After concentration, crude Citrullus lanatus seed oil was immediately placed in a hot air oven maintained at $60^{\circ} \mathrm{C}$ for $24 \mathrm{~h}$ to ensure complete removal of solvents. The concentrated oil (642 ml) sample was then stored in a bottle in a cool dry place until degumming.

\footnotetext{
Percentage yield $=\frac{\text { Mass of the oil extracted }}{\text { Mass of the seed before extraction }} \times 100$
} 


\section{Degumming of Citrullus lanatus Seed Oil}

The Citrullus lanatus seed oil contains phosphatides, gums and other complex compounds which can promote hydrolysis (increase in free fatty acid) of oil during storage. The crude oil sample was heated to $80^{\circ} \mathrm{C}$, mixed with water ( $5 \%$ vol) and stirred for 15 minutes by magnetic stirrer. Then the mixture was centrifuged (7000 rpm) for 20 minutes. ${ }^{12}$ Precautions were taken in order to prevent the introduction of air and subsequent oxidation of oil. Due to this, phosphatides and other impurities were settled down and were centrifuged out from the degummed oil.

\section{Preparation of Sheep Red Blood Cell (SRBC) as an Antigen}

Fresh blood was collected from sheep sacrificed in local slaughter house. Sheep red blood cells (SRBC) were washed three times in normal saline and RBC of this suspension was adjusted to a concentration of $5 \times 10^{9}$ cells per $\mathrm{ml}$ for immunization and challenge. ${ }^{13}$

\section{SRBC-induced Delayed Type Hypersensitivity Reaction (DTH response)}

The animals were grouped in eight (8) cages of four (4) rats per cage. DTH response was induced in rats using $\mathrm{SRBC}$ as an antigen according to Doherty method. ${ }^{14}$

\section{Humoural Antibody Response (HA response)}

A total of forty four (44) rats were divided into eleven (11) groups of four (4) rats per cage was used in this study. Groups 1 and 2 acted as control groups treated with $100 \mathrm{mg} / \mathrm{kg}$ b.w. of crude and degummed oil without being challenged with $0.05 \mathrm{ml}$ of $5 \times 10^{9} \mathrm{SRBC}$, Group- 3 was standard control treated with $5 \mathrm{omg} / \mathrm{kg}$ b.w. of levamisole after being challenged with SRBC, group 4 was treated with $5 \%$ DMSO after SRBC challenge, group 5 received 5\% DMSO without SRBC challenge, groups 6 and 7 received $50 \mathrm{mg} / \mathrm{kg}$ b.w of degummed and crude oil respectively, groups 8 and 9 received 10omg/ $\mathrm{kg}$ b.w. of degummed and crude oil respectively while groups 10 and 11 received $150 \mathrm{mg} / \mathrm{kg}$ b.w. respectively. Crude and degummed oil was administered at different doses (50, 100 and $150 \mathrm{mg} /$ $\mathrm{kg}$ b.w.) and the rats were immunized with $10 \%$ suspension of SRBC on day o intraperitonially (i.p.) and treatment continued till the $7^{\text {th }}$ day of the experiment, they were challenged, blood samples were collected from the retro orbital plexus of individual animals for primary antibody response and on day 14 for secondary antibody response and their antibody titre from serum was determined according to Puri et al. ${ }^{15}$ Serum was diluted in $50 \mu \mathrm{l}$ of phosphate buffer 
saline (PBS) of pH 7.2 with two fold serial dilution in 96-well microtire plate and mixed with $50 \mu \mathrm{l} 1 \% \mathrm{SRBC}$ suspension in PBS. Plates were kept at room temperature for 2 hour. The value of antibody titre was considered at the highest serum dilution showing visible haemaglutination and expressed as HA titre.

\section{Preparation of Candida albicans for animal study.}

Stock cultures of $C$. albicans $\mathrm{SC} 5413$ cells were kept at $4^{\circ} \mathrm{C}$ and passaged once a month to maintain viability. Before each experiment, C. albicans $\mathrm{SC}_{5413}$ cells were grown in Sabouraud's dextrose agar at $37^{\circ} \mathrm{C}$ for $48 \mathrm{~h}$. Cells were harvested by centrifugation at $3500 \times g$ for $10 \mathrm{~min}$. Cells were washed three times with $50 \mathrm{ml}$ of sterile non pyrogenic phosphate buffered-saline (PBS), counted with a haemacytometer, and resuspended in PBS to the required concentrations $\left(1 \times 10^{7} \mathrm{CFU} / \mathrm{ml}\right)$.

\section{Induction of oropharyngeal infection with Candida albicans in rat}

After seven (7) consecutive days of immunosupression with $50 \mathrm{mg} / \mathrm{kg}$ body weight of pyrogallol. Disseminated candidiasis infection was induced by oral

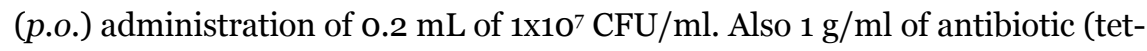
racycline) was administered po for three days (to eliminate competitive normal flora) during inoculation of Candida albicans SC5413 cells. Twenty-four (24), forty-eight (48) and seventy-two (72) hours after infection, nine animals were euthanised to check the effectiveness of the infection by assessing the fungal load in the kidneys. After which $48 \mathrm{~h}$ was chosen for the study.

\section{Full blood count assays}

Full blood counts including packed cell volume (PCV), Haemoglobin (Hb), red blood cell (RBC), white blood cell (WBC), differential WBC (lymphocytes and mixed) were estimated using the Sysmsex $囚$ Automated Haematology Analyzer (KX-21N, Sysmex Corporation, Kobe-Japan). The whole sample method was used where blood was mixed manually, and then fed into the transducers. The transducer chamber has a minute hole called the aperture. On both sides of the aperture, there are electrodes between which flows direct current. Blood cells pass through the aperture, causing direct current resistance to change between the electrodes. As direct current changes, the blood cell size is detected as electric pulses. Blood cell count is then calculated by counting the pulses, and a histogram of blood cell sizes is plotted by determining the pulse sizes. Also, analyzing a histogram makes it possible to obtain various analysis data including differential whole blood count, red cell indices and derived values. 


\section{CD4+ T-lymphocyte count}

The CD4+ lymphocytes were determined using the CyFlow® Automated Cell Counter (Partec, Germany). The Counter uses a 'no lyse, no wash' procedure for CD4 counting. ${ }^{16}$ EDTA-anticoagulated blood (fifty microliters) were added to $10 \mu \mathrm{l}$ of monoclonal antibodies. After $15 \mathrm{~min}$ of incubation, $1 \mathrm{ml}$ of no lyse dilution buffer was added and the sample tube was attached to the Counter for automated counting. Results were available in 2 minutes and were expressed in a histogram (CD4+ cells/ $\mu \mathrm{l})$.

\section{Cytokine assays}

Enzyme-linked immunosorbent assay. Quantification of each cytokine in the serum was determined using commercially available ELISA kits (Vector Best, Russia). One hundred microlitre ( $100 \mu \mathrm{l})$ of Solution for Sample Dilution (SSD) (Vector Best, Russia) was added to each well, then $100 \mu \mathrm{l}$ of calibration, sample and control per well. It was sealed with adhesive film and incubated for two (2) hours at $37^{\circ} \mathrm{C}$. The wells were aspirated and washed (5 times) with PBS-T $\times 25$ and blotted with a clean cotton gauze. Conjugate No.1 (100 $\mu$ l) (Vector Best, Russia) was added to each well, covered with new adhesive and incubated for an hour at $37^{\circ} \mathrm{C}$. After incubation, the wells were washed (5 times) as described before, then Conjugate No.2 (100 $\mu \mathrm{l})$ was added to each well and covered with new adhesive strip and incubated for 30 minutes and washed as stated above. Tetramethylbenzidine (TMB) solution (100 $\mu \mathrm{l}$ ) (Vector Best, Russia) was added to each well and incubated at $25^{\circ} \mathrm{C}$ for 25 minutes and protected from light. Stop solution was added to each well. Optical density of IL-10 was determined within 10 minutes using microplate reader set at $450 \mathrm{~nm}$. Same was carried out for IgA, TNF- $\alpha$, and IFN- $\gamma$. All cytokines and IgA concentrations (in picograms per milliliter) were determined by comparison with the standard curve.

\section{Data analysis}

The data obtained from this study were expressed as means \pm standard deviation (SD). Statistical comparisms between the groups were done using one way analysis of variance (ANOVA). Whereas the means were separated using Duncan's Multiple Range Test of $\mathrm{p}<0.05$. 


\section{RESULTS}

Percentage Yield: The percentage yield of the oil was $26.40 \%$.

\section{Delayed-type hypersensitivity (DTH) test}

The result of DTH in Figure 1 shows that there was significant increase $(\mathrm{p}<0.05)$ in the hind paw oedema of rats treated with crude and degummed oil (CO and DO respectively) after 24 hours when compared with the control. There was no significant increase ( $\mathrm{p}>0.05)$ in hind paw oedema of rats treated with both $25(5.17$ $\pm 0.29 \mathrm{~mm})$ and $50 \mathrm{mg} / \mathrm{kg}$ b.w. $(5.23 \pm 0.25 \mathrm{~mm})$ of degummed oil when compared with the standard control $(4.87 \pm 0.21 \mathrm{~mm})$. But there was a significant ( $\mathrm{p}$ $<0.05)$ increase in hind paw oedema of rats treated with $100 \mathrm{mg} / \mathrm{kg}$ b.w. $(6.10 \pm$ o.66) of degummed oil when compared to the standard control $(4.87 \pm 0.21 \mathrm{~mm})$. For the CO, paw oedema of all the treated groups were found to be significantly ( $\mathrm{p}<0.05$ ) higher when compared with both normal and standard control. After 48 hours, the paw oedema of the normal control $(6.10 \pm 0.46 \mathrm{~mm})$ and standard control $(4.50 \pm 0.40 \mathrm{~mm}$ ) increased significantly ( $\mathrm{p}<0.05)$ compared to their 24 hours values. A significant ( $<<0.05$ ) decrease in hind paw oedema of rats treated with $100 \mathrm{mg} / \mathrm{kg}$ b.w. (3.90 $\pm 0.53 \mathrm{~mm})$ after 48 hours was observed when compared with $6.10 \pm 0.66 \mathrm{~mm}$ obtained after 24 hours. There was also a significant $(\mathrm{p}<0.05)$ decrease in hind paw oedema of groups $2(4.867 \pm 0.57 \mathrm{~mm}), 3(3.900$ $\pm 0.53 \mathrm{~mm}), 4(5.200 \pm 0.27 \mathrm{~mm})$ and $6(3.133 \pm 0.321 \mathrm{~mm})$ after 48 hours when compared with the normal control $(6.100 \pm 0.458 \mathrm{~mm})$.

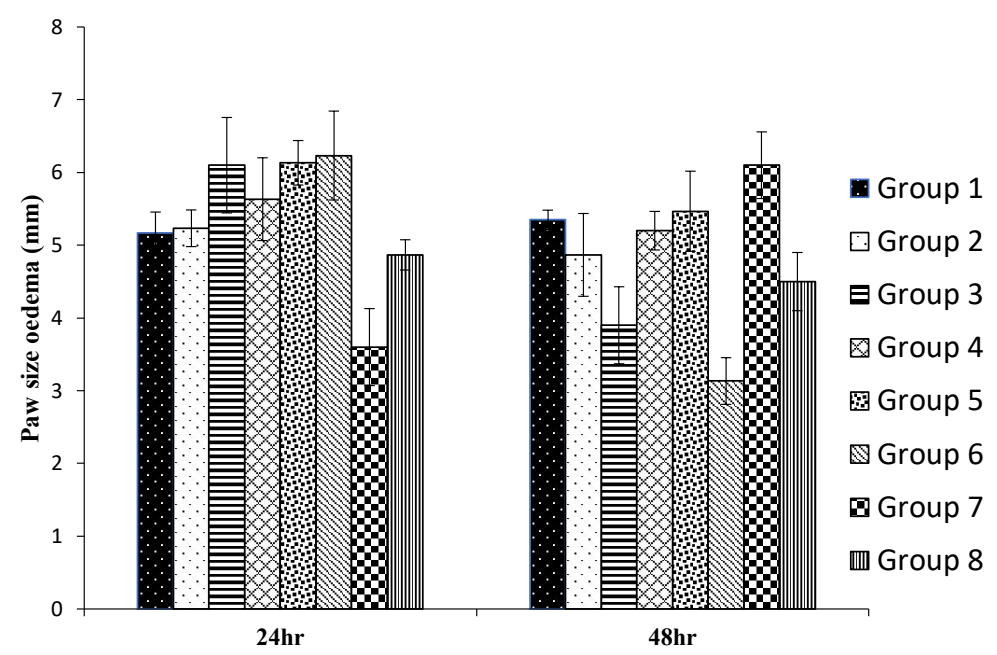

Figure 1: Paw size oedema of different group challenged with SRBC

Results expressed as means $\pm \mathrm{SD}$ 


\section{Key:}

Group 1 (25 mg/kg b.w.) \{Degummed\}

Group2 (50mg/kg b.w.) \{Degummed\}

Group 3 (100mg/kg b.w.) \{Degummed)

Group 4 (25 mg/kg b.w.) \{Crude\}

Group 5 (50 mg/kg b.w.) \{Crude)

Group 6 (100 mg/kg b.w.) \{Crude\}

Group 7 (normal control) (DMSO)

Group 8 (Standard Control) $\{25 \mathrm{mg} / \mathrm{kg}$ b.w. Levamisole $\}$

\section{Humoural antibody titre using SRBC as an antigen}

Figure 2 shows that there was non-significant ( $p>0.05$ ) decrease in secondary antibody titre values when compared with the primary antibody titre values. In the primary antibody titre, there was a significant increase $(\mathrm{p}<0.05)$ in group 1 when compared with that of group 2. However, there was no significant increase ( $p>0.05$ ) in group 2 when compared with group 3 . Similarly, a significant increase $(\mathrm{p}<0.05)$ in group 4 when compared with group. In the same vein, group 7 exhibited a significant increase $(\mathrm{p}<0.05)$ when compared with group 6. But there was no significant increase ( $p>0.05$ ) in group 9 when compared with group 8. There was no significant increase ( $p>0.05)$ in group 10 when compared with group 11.

In the secondary immune response, there was a decrease in the titre when compared with the primary antibody response. There was a significant increase ( $\mathrm{p}<0.05$ ) in group 1 when compared with group 2 but the titres are quite lower than the primary titres. There was also a significant increase $(\mathrm{p}<0.05)$ in group 3 when compared with group 4 . Also group had a significant increase $(\mathrm{p}<0.05)$ when compared with group 5 but there was no significant increase ( $p>0.05)$ in group 2 when compared with group 5 . In the same vein, there was no significant difference ( $p>0.05$ ) between groups 6 and 7, just as there was no significant increase ( $p>0.05$ ) in group 10 when compared with group 11; however group 9 shows a significant increase $(\mathrm{p}<0.05)$ in humoural antibody titre when compared with group 8 . 

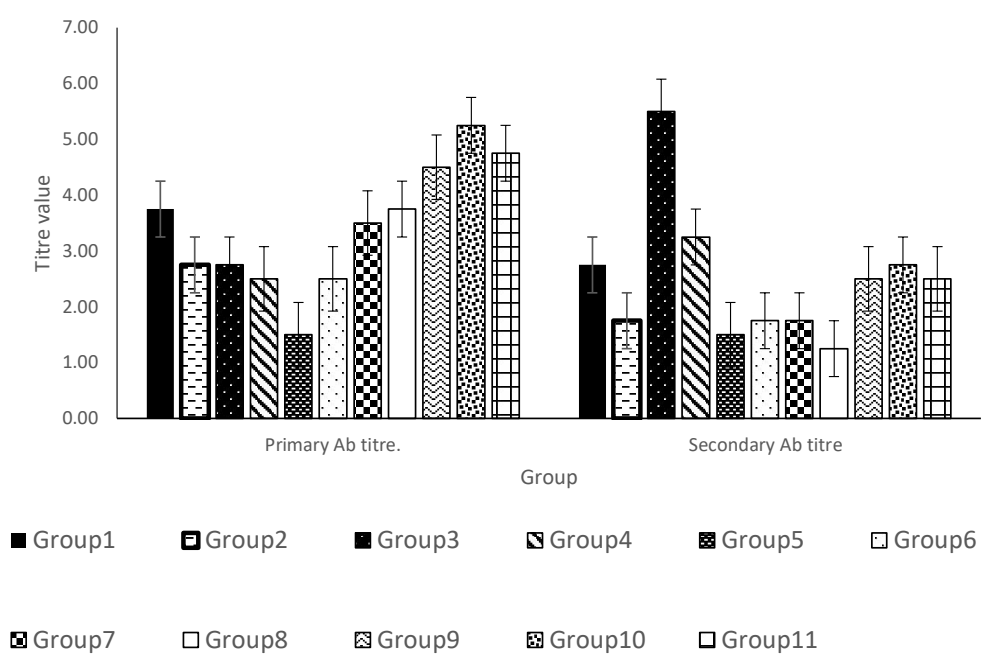

Figure 2: Humoural antibody titre of rats challenge and unchallenged with SRBC Means with different superscript within rows are significantly different $(P<0.05)$

Results expressed as means $\pm \mathrm{SD}$

Key:

Group 1 (10omg/kg b.w. of crude oil)

Group 2 (100mg/kg b.w. of degummed oil)

Group 3 (challenged and treated with $50 \mathrm{mg} / \mathrm{kg}$ b.w. of levamisole)

Group 4 (challenged and treated with DMSO)

Group 5 (unchallenged and treated with DMSO)

Group 6 (50mg/kg b.w. of degummed oil)

Group 7 (50mg/kg b.w. of crude oil)

Group 8 (10omg/kg b.w. of degummed oil)

Group 9 (100mg/kg b.w. of crude oil)

Group 10 (150mg/kg b.w. of degummed oil)

Group 11 (150mg/kg b.w. of crude oil)

\section{Effect of Citrullus lanatus seed oil on complete blood and CD 4 count at $7^{\text {th }}$ and $14^{\text {th }}$ days of treatment}

The result shows no significant increase ( $\mathrm{p}>0.05$ ) in PCV, Hb, WBC, lymphocyte, neutrophil, eosinophil, monocyte, platelet and RBC among the groups treated with the oil except groups 4 and 9 which showed a significant increase ( $\mathrm{p}<0.05$ ) in PCV values while Hb showed a significance increase $(\mathrm{p}<0.05)$ in groups 4, 5 and 9 when compared with group 10. WBC had significant increase ( $\mathrm{p}<0.05$ ) in groups 3 and 6 when compared with group 10. Also neutrophil significantly increased $(\mathrm{p}<0.05)$ in group 5 when compared with group 10. Red 
blood cell (RBC) showed a significant increase $(\mathrm{p}<0.05)$ in groups 5 and 6 when compared with group 10 . The $\mathrm{CD} 4$ significantly increased in groups 4,7 and 9 when compared with group 10.

After 14 days of treatment, there was significant increase (p < 0.05) in PCV and $\mathrm{Hb}$ conc. of groups 4, 5, 6, 7, 8 and 9, while group 6 had a significant increase $(\mathrm{p}<0.05)$ in WBC, groups 5 and 7 also had a significant increase $(\mathrm{p}<0.05)$ in platelet values when compared with group 10. However, lymphocyte, neutrophil, monocyte and eosinophils had a no significant increases ( $p>0.05$ ) in their values when compared with group 10 . But the $\mathrm{CD} 4$ count values decreased $(\mathrm{p}>$ 0.05) below group 10 (normal control).

Table 1A: Effect of Citrullus lanatus Seed Oil on Complete Blood Count at $7^{\text {th }}$ day of Treatment

\begin{tabular}{|c|c|c|c|c|c|c|c|c|}
\hline Groups & PCV (\%) & $\mathrm{Hb}(\mathrm{g} / \mathrm{dll})$ & $\operatorname{WBC}\left(x 10^{\circ} L\right)$ & Lymph (\%) & Neut (\%) & Platelet(x $\left.10^{9}\right)$ & $\operatorname{RBC}\left(10^{12}\right)$ & Mono (\%) \\
\hline 1 & 40.33+4.51 10x & $12.17 \pm 1.00^{\text {tac }}$ & $8.93 \pm 1.25^{b}$ & $66.67 \pm 2.08^{\mathrm{atc}}$ & $27.00 \pm 3.46^{\text {bc }}$ & $437.00 \pm 14.00$ & $6.90 \pm 1.00^{\mathrm{bac}}$ & $4.33 \pm 0.58^{8 \mathrm{~b}}$ \\
\hline 2 & $36.33 \pm 3.06^{a}$ & $11.10 \pm 0.50^{\mathrm{a}}$ & $14.00 \pm 1.35^{\text {te }}$ & $74.33 \pm 2.08^{\text {bicd }}$ & $19.67 \pm 1.53^{3 \mathrm{~b}}$ & $595.33 \pm 19.50$ & $5.77 \pm 0.35^{a}$ & $4.00 \pm 1.00^{a b}$ \\
\hline 3 & $35.67 \pm 5.51^{\mathrm{a}}$ & $11.07 \pm 1.01^{13}$ & $13.87 \pm 1.07 \mathrm{de}$ & $72.67 \pm 3.06^{\text {bed }}$ & $21.00 \pm 1.73^{36}$ & $570.67 \pm 83.12$ & $6.83 \pm 0.50^{\mathrm{acc}}$ & $3.67 \pm 1.53^{3 b}$ \\
\hline 4 & $46.33 \pm 2.52^{\circ}$ & $13.30 \pm 0.70^{\circ}$ & $10.12 \pm 1.38^{\text {bo }}$ & $67.33 \pm 2.52^{2 \mathrm{ac}}$ & $27.33 \pm 3.06^{\text {bc }}$ & $605.33 \pm 230.66$ & $7.27 \pm 0.58^{\mathrm{bc}}$ & $3.67 \pm 1.53^{3 \mathrm{~b}}$ \\
\hline 5 & $41.67 \pm 2.08^{\text {tic }}$ & $12.77 \pm 0.59 \mathrm{gcc}$ & $12.40 \pm 0.80$ de & $57.33 \pm 18.9^{2}$ & $35.00 \pm 15.13^{c}$ & $568.67 \pm 115.45$ & $7.80 \pm 0.70^{\circ}$ & $6.33 \pm 1.53^{\mathrm{b}}$ \\
\hline 6 & $42.00 \pm 4.58^{\text {itc }}$ & $12.23 \pm 0.72^{\text {atc }}$ & $14.57 \pm 1.40^{\circ}$ & $71.33 \pm 3.21^{\text {tod }}$ & $23.00 \pm 3.00^{206}$ & $597.33 \pm 57.14$ & $7.17 \pm 0.42^{20 b}$ & $4.00 \pm 2.00^{200}$ \\
\hline 7 & $40.67 \pm 4.04^{\text {atc }}$ & $12.43 \pm 0.9$ talc $^{\text {alc }}$ & $12.63 \pm 0.67$ de & $64.33 \pm 8.02^{200}$ & $28.00 \pm 8.54^{\text {toc }}$ & $531.33 \pm 131.44$ & $7.27 \pm 0.70^{\text {bc }}$ & $5.67 \pm 1.15^{b}$ \\
\hline 8 & $39.33 \pm 2.08$.86 & $11.80 \pm 0.44^{\text {ab }}$ & $10.87 \pm 1.94^{\text {krd }}$ & $71.00 \pm 1.000^{\text {bod }}$ & $23.00 \pm 2.65^{50}$ & 597.33ะ117.75 & $6.67 \pm 0.61^{130}$ & $5.33 \pm 2.52^{20 \mathrm{~b}}$ \\
\hline 9 & $44.33 \pm 1.53^{30}$ & $13.03 \pm 0.40^{\text {bc }}$ & $13.53 \pm 3.16^{\text {de }}$ & $79.67 \pm 3.79^{\text {dd }}$ & $17.33 \pm 4.04^{206}$ & $525.33 \pm 129.68$ & $7.50 \pm 0.62^{c}$ & $2.67 \pm 0.58^{a}$ \\
\hline 10 & $38.67 \pm 2.52^{20 \mathrm{~b}}$ & $11.00 \pm 0.85^{\mathrm{a}}$ & $5.77 \pm 2.29^{\circ}$ & $82.67 \pm 5.86^{\mathrm{cd}}$ & $12.67 \pm 5.51^{\mathrm{a}}$ & $462.67 \pm 31.64$ & $6.20 \pm 0.26^{\mathrm{ab}}$ & $3.67 \pm 0.58^{2 ⿰ \mathrm{~b}}$ \\
\hline P-value & 0.031 & 0.006 & 0.000 & 0.014 & 0.019 & 0.591 & 0.020 & 0.133 \\
\hline
\end{tabular}

Means with different superscript within rows are significantly different $(\mathrm{P}<0.05)$

Results expressed as means $\pm \mathrm{SD}$

\section{Key:}

Group 1= inoculated without immunosuppression

Group 2=suppressed without inoculation

Group $3=$ inoculated + suppresses without treatment

Group 4=inoculated + suppressed + treated with $300 \mathrm{mg} / \mathrm{kg}$ body weight of DO

Group $5=$ inoculated + suppressed + treated with $500 \mathrm{mg} / \mathrm{kg}$ bw DO

Group 6= inoculated + suppressed + treated with $300 \mathrm{mg} / \mathrm{kg}$ bw CO

Group $7=$ inoculated + suppressed + treated with $500 \mathrm{mg} / \mathrm{kg} \mathrm{bw} \mathrm{CO}$

Group $8=$ inoculated + suppressed + treated with $25 \mathrm{mg} / \mathrm{kg}$ bw levamisol

Group $9=$ inoculated + suppressed + treated with $5 \mathrm{mg} / \mathrm{kg}$ bw Fluconazole

Group 10=Normal control 
Table 1B: Effect of Citrullus lanatus seed oil on complete blood count at $14^{\text {th }}$ day of treatment

\begin{tabular}{|c|c|c|c|c|c|c|c|c|}
\hline Groups & $\operatorname{PCV}(\%)$ & $H b(g / d l)$ & WBC $(\times 109 / \mathrm{L}$ & Lymph $(\%)$ & $\operatorname{Neut}(\%)$ & Mono (\%) & Platelet $\left(x 1^{9}\right)$ & $\operatorname{RBC}\left(10^{12}\right)$ \\
\hline 1 & $46.00 \pm 3.00^{\circ}$ & $13.17 \pm 0.31^{c}$ & $9.60 \pm 0.20^{\mathrm{abc}}$ & $78.33 \pm 7.64$ & $22.33 \pm 4.16$ & $2.67 \pm 0.58$ & $666.33 \pm 140.5$ d & $7.70 \pm 0.10^{\mathrm{e}}$ \\
\hline 2 & $30.00 \pm 4.00^{2}$ & $9.93 \pm 1.04^{b}$ & $6.57 \pm 0.86^{\text {bb }}$ & $71.33 \pm 8.08$ & $24.33 \pm 9.29$ & $3.00 \pm 1.00$ & $478.00 \pm 42.67^{2 a c c}$ & $5.50 \pm 0.56^{a}$ \\
\hline 3 & $37.67 \pm 6.51^{b}$ & $8.77 \pm 0.72^{\mathrm{a}}$ & $7.33 \pm 0.83^{30 b}$ & $77.33 \pm 6.81$ & $17.67 \pm 7.77$ & $3.33 \pm 0.58$ & $542.00 \pm 60.56^{\text {abcd }}$ & $5.73 \pm 1.06^{\mathrm{bb}}$ \\
\hline 4 & $49.75 \pm 2.36^{\circ}$ & $13.33 \pm 0.40^{\circ}$ & $9.68 \pm 1.86^{\mathrm{atc}}$ & $73.25 \pm 14.86$ & $23.00 \pm 14.90$ & $2.50 \pm 0.58$ & $544.75 \pm 36.67$ abced & $7.28 \pm 0.53^{\text {te }}$ \\
\hline 5 & $50.50 \pm 3.70^{\circ}$ & $13.05 \pm 1.00^{\circ}$ & $10.50 \pm 0.43^{b c}$ & $80.50 \pm 6.95$ & $15.25 \pm 6.95$ & $3.00 \pm 0.82$ & $678.50 \pm 66.98$ & $7.05 \pm 0.37 \mathrm{ded}$ \\
\hline 6 & $48.25 \pm 1.50^{\circ}$ & $13.10 \pm 0.45^{\circ}$ & $11.75 \pm 4.07 c$ & $75.00 \pm 0.00$ & $20.50 \pm 1.29$ & $3.50 \pm 0.58$ & $645.25 \pm 115.35$ bocd & $7.35 \pm 0.17^{\mathrm{e}}$ \\
\hline 7 & $46.50 \pm 1.29 c$ & $12.53 \pm 0.17^{\natural}$ & $8.68 \pm 2.59 \mathrm{atc}$ & $73.00 \pm 6.06$ & $21.25 \pm 2.99$ & $3.50 \pm 0.58$ & $725.50 \pm 226.69 \mathrm{~d}$ & $7.00 \pm 0.61^{10 \mathrm{de}}$ \\
\hline 8 & $50.67 \pm 7.02^{\circ}$ & $13.33 \pm 1.00^{\circ}$ & $9.03 \pm 3.00^{3 \mathrm{abc}}$ & $77.00 \pm 2.00$ & $19.00 \pm 1.00$ & $3.33 \pm 0.58$ & $601.33 \pm 12.22$ abced & $7.27 \pm 0.328$ \\
\hline 9 & $45.33 \pm 4.04^{\circ}$ & $12.33 \pm 0.59 \mathrm{c}$ & $8.50 \pm 2.23^{\text {atc }}$ & $79.00 \pm 1.00$ & $16.33 \pm 2.08$ & $3.33 \pm 1.15$ & $408.33 \pm 102.05^{\mathrm{a}}$ & $6.43 \pm 0.2$ grod \\
\hline 10 & $38.67 \pm 2.52^{b}$ & $11.00 \pm 0.85^{b}$ & $5.77 \pm 2.29^{\mathrm{a}}$ & $82.67 \pm 5.86$ & $12.67 \pm 5.51$ & $3.67 \pm 0.58$ & $462.67 \pm 31.64^{b b}$ & $6.20 \pm 0.22^{63 \mathrm{coc}}$ \\
\hline P-value & 0.000 & 0.000 & 0.060 & 0.638 & 0.553 & 0.469 & 0.012 & 0.000 \\
\hline
\end{tabular}

Means with different superscript within rows are significantly different $(\mathrm{P}<0.05)$

Results expressed as means $\pm \mathrm{SD}$

Means with different superscript within rows are significantly different $(\mathrm{P}<0.05)$

Results expressed as means $\pm \mathrm{SD}$

\section{Key:}

Group 1= inoculated without immunosuppression

Group 2=suppressed without inoculation

Group 3=inoculated + suppressed without treatment

Group 4=inoculated + suppressed + treated with 300mg $/ \mathrm{kg}$ body weight of DO

Group $5=$ inoculated + suppressed + treated with $500 \mathrm{mg} / \mathrm{kg}$ bw DO

Group 6= inoculated + suppressed + treated with $300 \mathrm{mg} / \mathrm{kg}$ bw CO

Group $7=$ inoculated + suppressed + treated with $500 \mathrm{mg} / \mathrm{kg}$ bw CO

Group 8= inoculated + suppressed + treated with $25 \mathrm{mg} / \mathrm{kg}$ bw levamisol

Group 9= inoculated + suppressed + treated with $5 \mathrm{mg} / \mathrm{kg}$ bw Fluconazole

Group 10=Control 
Table 2: Effect of Citrullus lanatus Seed Oil on $\mathrm{CD}_{4}$ Count at $7^{\text {th }}$ and $14^{\text {th }}$ days of Treatment

\begin{tabular}{|c|c|c|}
\hline Groups & CD4 cells/ul at day-7 & CD4 cells/ul at day-14 \\
\hline 1 & $2206.33 \pm 285.50^{\mathrm{a}}$ & $2070.67 \pm 72.50^{\text {abc }}$ \\
\hline 2 & $1961.33 \pm 84.50^{\mathrm{a}}$ & $1387.00 \pm 438.63^{\mathrm{a}}$ \\
\hline 3 & $4602.33 \pm 2094.77^{\mathrm{abc}}$ & $1206.00 \pm 202.52^{\mathrm{a}}$ \\
\hline 4 & $6710.67 \pm 1788.6^{\mathrm{c}}$ & $1682.00 \pm 415.98^{\mathrm{ab}}$ \\
\hline 5 & $4434.67 \pm 464.95^{\text {abc }}$ & $1906.50 \pm 236.21^{\text {abc }}$ \\
\hline 6 & $3759.67 \pm 1007.46^{\text {ab }}$ & $1662.00 \pm 197.58^{\text {ab }}$ \\
\hline 7 & $6375.00 \pm 1507.84^{\text {bc }}$ & $2627.00 \pm 822.40^{\text {bc }}$ \\
\hline 8 & $4585.00 \pm 706.62^{2^{\text {abc }}}$ & $1945.00 \pm 284.45^{\text {acc }}$ \\
\hline 9 & $12952.67 \pm 2767.94^{\mathrm{d}}$ & $3980.33 \pm 1082.47^{\mathrm{d}}$ \\
\hline 10 & $2837.33 \pm 1002.07^{\mathrm{a}}$ & $2946.33 \pm 1002.07^{\mathrm{c}}$ \\
\hline$p$-value & 0.000 & 0.000 \\
\hline
\end{tabular}

Means with different superscript within rows are significantly different $(\mathrm{P}<0.05)$

Results expressed as means $\pm \mathrm{SD}$

Key:

Group 1= inoculated without immunosuppression

Group 2=suppressed without inoculation

Group 3=inoculated + suppressed without treatment

Group 4=inoculated + suppressed + treated with 300mg $/ \mathrm{kg}$ body weight of DO

Group $5=$ inoculated + suppressed + treated with $500 \mathrm{mg} / \mathrm{kg}$ bw DO

Group $6=$ inoculated + suppressed + treated with $300 \mathrm{mg} / \mathrm{kg} \mathrm{bw} \mathrm{CO}$

Group $7=$ inoculated + suppressed + treated with $500 \mathrm{mg} / \mathrm{kg}$ bw CO

Group 8= inoculated + suppressed + treated with $25 \mathrm{mg} / \mathrm{kg}$ bw levamisol

Group 9= inoculated + suppressed + treated with $5 \mathrm{mg} / \mathrm{kg}$ bw Fluconazole

Group 10=Control

\section{Effect of Citrullus lanatus seed oil on cytokines at $7^{\text {th }}$ and $14^{\text {th }}$ days of treatment}

Figures $3 \mathrm{~A}-3 \mathrm{D}$ showed that at day 7 , TNF- $\alpha$ significantly $(p<0.05)$ increased in groups $4(56.20 \pm 23.86), 5(43.70 \pm 11.75)$ and $8(43.17 \pm 4.00)$ when compared with group $10(16.43 \pm 15.36)$. There was no significant ( $p>0.05)$ decrease in group 2 when compared with that of groups $1(24.43 \pm 101.95)$ and $3(22.03 \pm 60)$. At day 14 , there was a significant $(p<0.05)$ increase in TNF- $\alpha$ 
in groups $4(41.63 \pm 9.52)$ and $8(52.00 \pm 7.44)$ when compared with groups 2 $(14.03 \pm 1.72)$ and $10(21.17 \pm 10.32)$. IFN $-\gamma$ significantly $(p<0.05)$ increased in group $4(352.60 \pm 138.36)$ at day 7 when compared with groups $2(135.83 \pm 11.10)$ and $10(118.67 \pm 18.75)$ while at day 14 , there was a significant $(p<0.05)$ decrease in groups 4 (209.93 \pm 13.42$), 5(204.70 \pm 26.73), 8(198.50 \pm 18.23)$ and 9 $(190.90 \pm 18.23)$ compared with that of group $3(83.73 \pm 23.02)$. Between days 7 and 14, the expression of IFN- $\gamma$ was decreased just like that of TNF- $\alpha$.

However, the concentration of IL-10 and IgA increased in response to C. albican infection between days 7 and 14. There was a significant $(p<0.05)$ increase in IL-10 concentrations in all the groups when compared with that of group 2 $(5.56 \pm 0.77)$ rats. At day 7 , IgA significantly $(p<0.05)$ increased in groups 5 $(27.20 \pm 2.28)$ and $7(27.00 \pm 5.72)$ when compared with groups $2(7.83 \pm 4.96)$ and $10(21.67 \pm 6.15)$.

At day 14, there was a significant $(p<0.05)$ increase IgA in groups 4

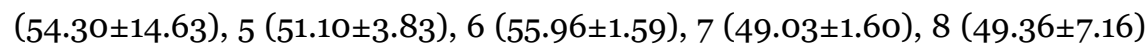
and $9(63.37 \pm 13.91)$ when compared with that of groups $2(8.20 \pm 1.76)$ and 10 (18.40 \pm 5.99$)$.

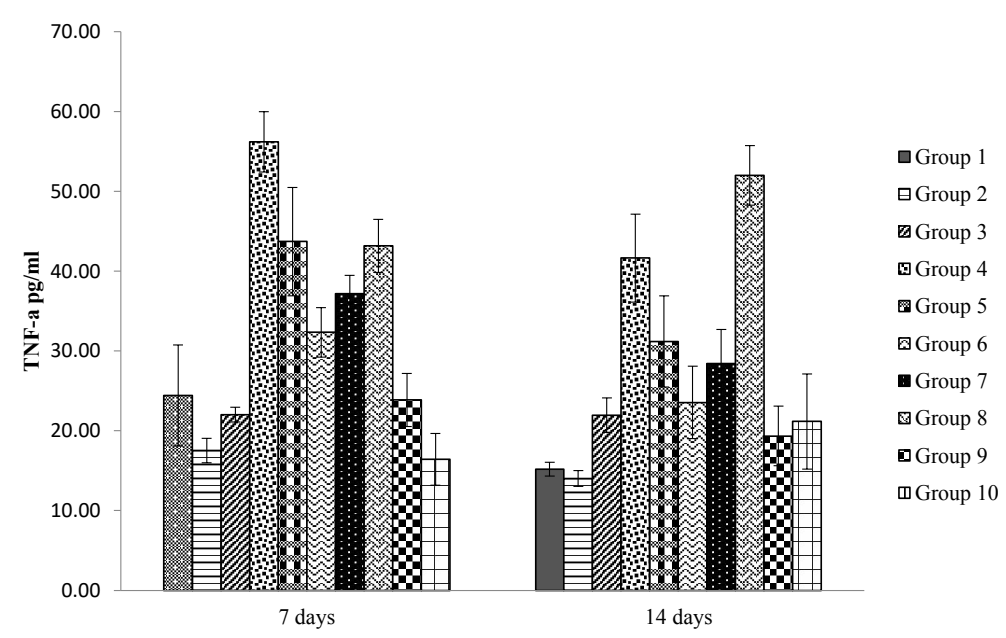

Figure 3A: Tumour Necrosis Factor-a concentration at days 7 and 14 of treatment

Means with different superscript within rows are significantly different $(\mathrm{P}<0.05)$. Results expressed as means $\pm \mathrm{SD}$ 


\section{Key:}

Group 1= inoculated without immunosuppression

Group 2=suppressed without inoculation

Group 3=inoculated + suppressed without treatment

Group 4=inoculated + suppressed + treated with $300 \mathrm{mg} / \mathrm{kg}$ body weight of DO

Group 5 =inoculated + suppressed + treated with $500 \mathrm{mg} / \mathrm{kg}$ bw DO

Group $6=$ inoculated + suppressed + treated with $300 \mathrm{mg} / \mathrm{kg}$ bw CO

Group 7 = inoculated + suppressed + treated with $500 \mathrm{mg} / \mathrm{kg} \mathrm{bw} \mathrm{CO}$

Group 8= inoculated + suppressed + treated with $25 \mathrm{mg} / \mathrm{kg}$ bw levamisole

Group $9=$ inoculated + suppressed + treated with $5 \mathrm{mg} / \mathrm{kg}$ bw Fluconazole Group 10=Control

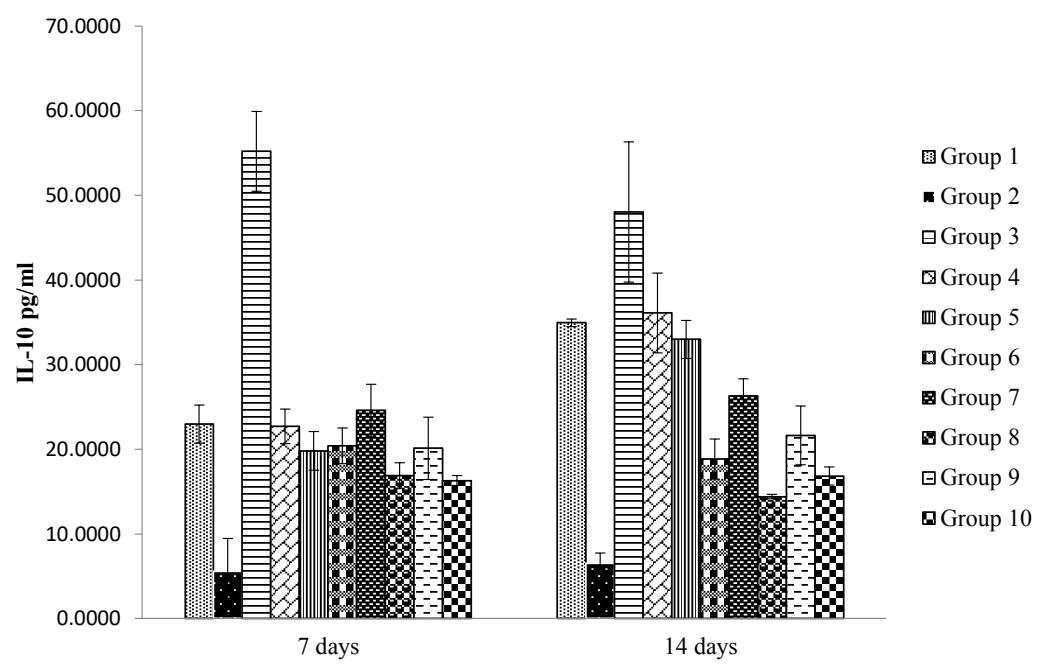

Figure 3B: $I L-10$ expression at $7^{\text {th }}$ and $14^{\text {th }}$ day of treatment.

\section{Key:}

Group 1= inoculated without immunosuppression

Group 2=suppressed without inoculation

Group 3=inoculated + suppressed without treatment

Group 4=inoculated + suppressed + treated with $300 \mathrm{mg} / \mathrm{kg}$ body weight of DO

Group $5=$ inoculated + suppressed + treated with $500 \mathrm{mg} / \mathrm{kg}$ bw DO

Group 6= inoculated + suppressed + treated with $300 \mathrm{mg} / \mathrm{kg}$ bw CO

Group $7=$ inoculated + suppressed + treated with $500 \mathrm{mg} / \mathrm{kg} \mathrm{bw} \mathrm{CO}$

Group 8= inoculated + suppressed + treated with $25 \mathrm{mg} / \mathrm{kg}$ bw levamisole

Group $9=$ inoculated + suppressed + treated with $5 \mathrm{mg} / \mathrm{kg}$ bw Fluconazole

Group 10=Control 


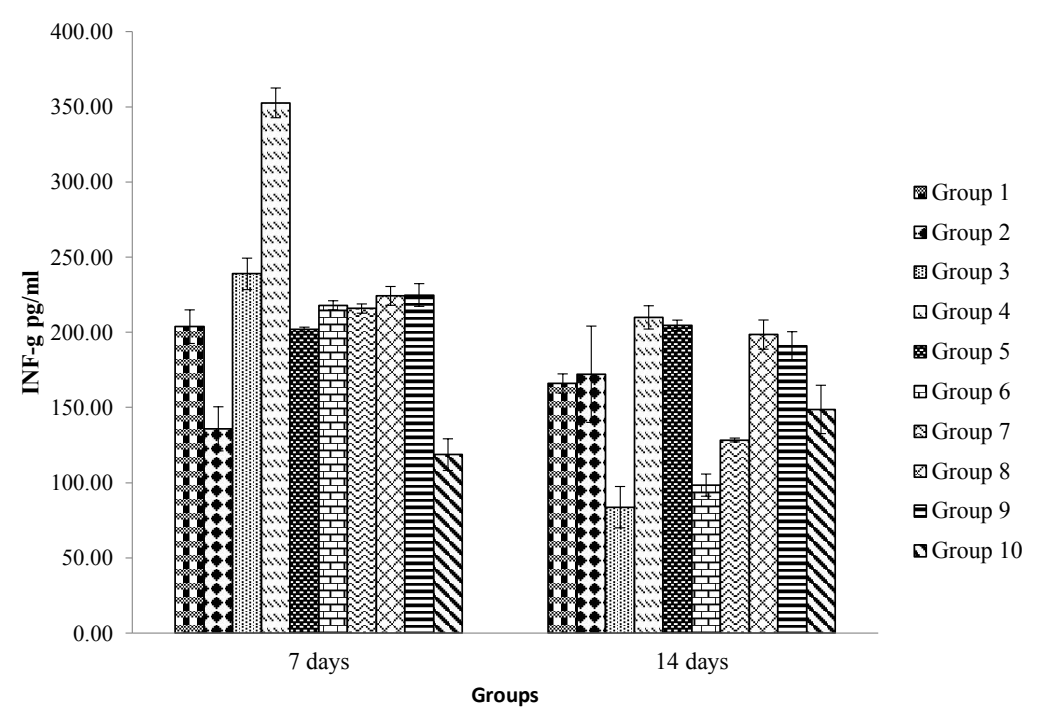

Figure 3C: Interferon gamma expression at $7^{\text {th }}$ and $14^{\text {th }}$ days of treatment.

Means with different superscript within rows are significantly different $(\mathrm{P}<0.05)$

Results expressed as means $\pm \mathrm{SD}$

\section{Key:}

Group 1= inoculated without immunosuppression

Group 2=suppressed without inoculation

Group 3=inoculated + suppressed without treatment

Group 4=inoculated + suppressed + treated with 300mg/kg body weight of DO

Group $5=$ inoculated + suppressed + treated with $500 \mathrm{mg} / \mathrm{kg}$ bw DO

Group 6= inoculated + suppressed + treated with $300 \mathrm{mg} / \mathrm{kg}$ bw CO

Group $7=$ inoculated + suppressed + treated with $500 \mathrm{mg} / \mathrm{kg}$ bw CO

Group $8=$ inoculated + suppressed + treated with $25 \mathrm{mg} / \mathrm{kg}$ bw levamisole

Group 9= inoculated + suppressed + treated with $5 \mathrm{mg} / \mathrm{kg}$ bw Fluconazole

Group 10=Control 


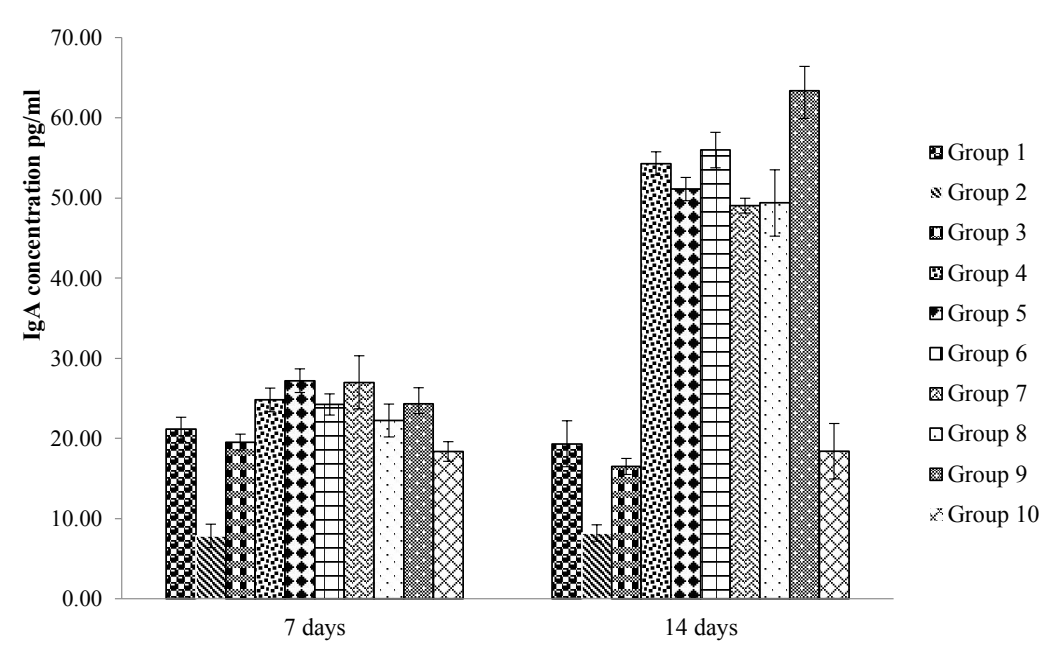

Figure 3D: Immunoglobulin A production at $7^{\text {th }}$ and $14^{\text {th }}$ days treatment.

Means with different superscript within rows are significantly different $(\mathrm{P}<0.05)$

Results expressed as means $\pm \mathrm{SD}$

\section{Key:}

Group 1= inoculated without immunosuppression

Group 2=suppressed without inoculation

Group 3=inoculated + suppressed without treatment

Group 4=inoculated + suppressed + treated with $300 \mathrm{mg} / \mathrm{kg}$ body weight of DO

Group $5=$ inoculated + suppressed + treated with $500 \mathrm{mg} / \mathrm{kg}$ bw DO

Group $6=$ inoculated + suppressed + treated with $300 \mathrm{mg} / \mathrm{kg}$ bw CO

Group $7=$ inoculated + suppressed + treated with $500 \mathrm{mg} / \mathrm{kg} \mathrm{bw} \mathrm{CO}$

Group $8=$ inoculated + suppressed + treated with $25 \mathrm{mg} / \mathrm{kg}$ bw levamisole

Group $9=$ inoculated + suppressed + treated with $5 \mathrm{mg} / \mathrm{kg}$ bw Fluconazole Group 10=Control.

\section{DISCUSSION}

Delayed type-hypersensitivity (DTH) response is used as a reflection of the development of immunity that is antigen specific. DTH response is also used to correlate T-cell response by lymphocyte proliferation which causes inflammation. Increase in DTH reaction in response to SRBC is an indication of normal inflammatory response. But after 48 hours, there was a significant decrease $(\mathrm{p}<0.05)$ in the paw-sized oedema of crude and degummed oil treated groups (groups 1-3) in a dose dependent manner. These results suggest that both deg- 
ummed and crude oil which is rich in n-6 poly unsaturated fatty acids exhibited modification of inflammatory responses by the stimulating Th1 cell to effectively respond to inflammation. Previous studies showed that inclusion of n-3 PUFAs significantly decreased DTH response when compared to diets high in n-6 PUFAs. ${ }^{17,18}$ This study has shown that the crude and degummed oil exhibited anti-inflammatory activity but was expressed more in the crude oil than the degummed oil. DTH tests are considered a recall response that is intrinsically different from the initial response to antigen by naïve T-cells. ${ }^{19}$

The humoural antibody titre (Figure 2) shows no significant increase ( $p>0.05$ ) between group 6 (50 mg/kg b.w. of degummed oil) and group 7 (50 mg/kg b.w. of crude oil), probably the dosage did not achieve bioavailability to express any significant difference. It was observed that there was a reduction in the secondary titre values as shown in Figure 2 when compared with the primary titre values, except for groups 4, 4 and 5. The observed suppressive effect on the secondary anti-SRBC titres suggests that the oil exerted inhibition of immuno-regulatory functions as the treatment progressed. The secondary immune response mechanism is through the selection of $B$ cells which has a high affinity for a given antigen; and this occurs in the germinal centres of secondary lymphoid follicles and requires enzyme activation-induced cytidine deaminase (AID). ${ }^{20}$ The administration of the watermelon seed oil diminished retention period of the antigen (sheep red blood cell) at the germinal centre which is extremely important and might have affected the quality of secondary immune response observed in this study. The Ag-retaining reticulum of the germinal centers is comprised of specialised follicular dendritic cells (FDCs) that capture intact $\mathrm{Ag}$ in the form of $\mathrm{Ag}-\mathrm{Ab}$ complexes by means of complement receptors or Fc receptors or both. ${ }^{21}$

After seven days of treatment, there was increase in the haemoglobin, haematocrit, and total white blood cell count, monocyte and platelet count. This result agreed with the work of Bushra et al..$^{22}$ The oil might have acted on hematopoietic cells and activated their differentiation into target cells. Pyrogallol which is a reducing agent might have accumulated in the bone marrow and kidney leading to alterations in the erythropoietic process as shown in group 2. Anaemia is a common phenomenon in immunosuppressive conditions. ${ }^{23}$ The imbalance in redox reaction and inflammation brought by pyrogallol as well as Candida albicans created a hypoxic environment in the renal interstitium, (kidney being one of the target organs of oropharyngeal candidiasis) which resulted in impaired production of erythropoietin and subsequently result in anaemia. This however increases susceptibility to microbial infections, reactivation of "inactive" (normal flora) pathogens. Madhavi et al. ${ }^{11}$ observed that CLSO induced 
lyses of erythrocyte membrane. The erythrocyte membrane is analogous to the lysosomal membrane and its stabilization implies that the oil may as well stabilise lysosomal membrane. ${ }^{23}$

Neutrophil activation is said to be compromised in disseminating candidiasis, through oral mucosa. It is possible that oil utilised a peculiar defense mechanism which controlled the evasiveness of candidiasis. Gradual increase in lymphocyte (at day-14) might be due to increased cellular response to C. albicans infection. Polymorphonuclear cells (PMNs), monocytes and macrophages are important for the main innate effector response. Candida exerts stimulatory effects on platelets through the release of antimicrobial peptide which activates thrombopoeitic activity to release inflammatory mediators. The aggregation of platelets releases microbicidal or microbiostatic substances that are active against Candida spp. ${ }^{25}$

CD4 T-cells represent a unique branch of the adaptive immune system that is vital in achieving a regulated effective immune response to pathogens, and their proper functioning is crucial to our survival. Citrullus lanatus seed oil might have triggered the proliferation/differentiation of $\mathrm{CD} 4 \mathrm{~T}$-cells against candidiasis. CD4 T-cell-mediated resistance to candidiasis is thought to take place via the production of T helper-1 cytokines (such as gamma interferon [IFN-g] and interleukin-2.) that enhance the candidacidal activity of phagocytic cells. ${ }^{26,27}$ AIDS patients, with reduced populations of CD4 T-cells, are susceptible to oropharyngeal candidiasis. ${ }^{28}$

Cytokines investigated in this study were that of pro-inflammatory such as tumour necrosis factor $\alpha$ (TNF- $\alpha)$ and interferon $\gamma$ (IFN- $\gamma)$ and anti-inflammatory such as interleukine-10 (IL-10) cytokine. It will make a physiologic sense to say that $C$. albicans ellicit a normal inflammatory response (TNF- $\alpha$ and INF- $\gamma$ ) expression which was down regulated by the administration of Citrullus lanatus seed oil (CLSO). This cytokines regulate the growth and differentiation of different lymphocyte subsets. The oil exhibited more anti-inflammatory potentials, since it inhibited the expression of TNF- $\alpha$ and IFN- $\gamma$ at day 14 of the study. The anti-inflammatory activity of IL-10 dominated the inflammatory response to $C$. albicans resulting in decreases in pro-inflammatory cytokines investigated in this study. In addition, we observed that degummed oil [DO] (group 4 and 5) exerted more anti-inflammatory effect (day-14) probably due to enhanced nutritional values and removal of possible inhibitors of IL-10 in DO. IL-10 is a well-known anti-inflammatory cytokine and plays an important role in suppressing the inflammatory response in many in vitro or in vivo experimental models. ${ }^{28,29}$ It has been reported that IL-10 inhibits the release of pro- 
inflammatory cytokines INF- $\gamma$ and TNF- $\alpha$ by human monocyte/macrophage in response to polymethylmethacrylate (PMMA, spherical 1-10 $\mu \mathrm{m}$ ) particle challenge in vitro. ${ }^{30} \mathrm{TNF}-\alpha$ is essential for anti-Candida host defense through the recruitment of neutriphils and phagocytosis, and deficiency results in high mortality during experimental disseminated candidiasis. ${ }^{29} \mathrm{INF}-\gamma$ produced by CD4 T lymphocytes is also important for the stimulation of antifungal activity of PMNs. There is no report yet on cytokine analysis or immunoglobulin A (IgA) on both crude and degummed Citrullus lanatus oil. Sadeghi et al. ${ }^{31}$ reported a decrease in TNF- $\alpha$, IL-1 $\beta$ and IL-6 in response to dietary lipid (safflower oil, fish oil and coconut oil) in rats challenged with lipopolysaccharide (LPS).

Immunoglobulin A (IgA) is considered the isotype that predominantly mediates humoural immune defense at mucosal level..$^{32}$ The crude and degummed CLSO favoured immunoglobulin class switch to IgA after the rats were infected with Candida albicans $\mathrm{SC} 5314$ cells. The increase in IgA was sustained as the administration of the oil progressed up to day 14. Immunological protection of mucosal surfaces is mediated primarily by the secretory immune system, particularly immunoglobulin A (IgA) in secretions, which affords protection by inhibiting adherence and penetration of microorganisms and foreign proteins to mucosal tissues..$^{33}$ Mucosal IgA prevents attachment and penetration of microorganisms and molecular antigens, thereby blocking their potential effects on the host. ${ }^{34}$ Group 3 showed a decrease in IgA up to day-14. This could be as a result of weakened immune system by pyrogallol, which was administered throughout the period of the study. This findings suggests that CLSO could enhance the immunoglobulin switching to IgA antibody to confer protection against Candida albicans. This was affirmed by the inability of group 3 to mount immunological protection against Candida albicans when compared with treated groups.

This study demonstrated that Citrullus lanatus seed oil has anti-inflammatory property which was expressed more in the crude than the degummed counterpart. However, the oil did not have favorable therapeutic effects on immune system. 


\section{REFERENCES}

1. Harizi, H; Corcuff, J.B.; Gualde, N. Arachidonic-acid-derived eicosanoids: roles in biology and immunopathology. Trends Mol Med. 20o8, 14(10), 461-910

2. Josef, E.; Gerhard, L.; Marion, E.; Margot, G.; Horst, R.; Gerd, S. Induction of fatty acid synthesis is a key requirement for phagocytic differentiation of human monocytes. PNAS 2010, 107 (17), 7817-7822.

3. Ecker, J.; Langmann, T.; Moehle, S.G. Isomer specific effects of conjugated linoleic acid on macrophage ABCG1 transcription by a SREBP-1c dependent mechanism. Bioch and Biophy Res Comm. 2007, 352, 805-811.

4. Lisa, M.C.; Zena, W. Inflammatory Cells and Cancer. J Exp Med. 2oo1, 193(6), F23-26.

5. McCarberg, B.H.; Cryer, B. Evolving therapeutic strategies to improve nonsteroidal anti-inflammatory drug safety. Am $J$ Ther. 2014, 22, e167-e178.

6. Koeberle, A.; Werz, O. Multi-target approach for natural products in inflammation. Drug Discov Today 2014, 19(12), 1871-1882.

7. Atal, C.K.; Sharma, M.L.; Khariya, A. Immunomodulating agents of plant origin. J Ethnopharm. 1986; 18, 133-141.

8. Gul, S.; Rashid, Z.; Sarwer, G. Citrullus lanatus (Watermelon) As Diuretic Agent: An In vivo Investigation on Mice. Citrullus Lanatus (Watermelon) As Diuretic Agent: An In vivo Investigation on MiceCitrullus Lanatus (Watermelon) As Diuretic Agent: An In vivo Investigation on Mice Am J Drug Delivery and Therap. 2014, 1(4), 89-92.

9. Erukainure, O.L.; Oke, O.V.; Adenekan, S.O.; Ajiboye, J.A. Antioxidant activities, total phenolic and flavonoid levels of water melon rinds subjected to Saccharomyces solid media fermentation. Fermentation Tech and Bioeng. 2011, 2, 11 - 16.

10. Jamuna, K.S.; Ramesh, C.K.; Srinivasa, T.R.; Raghu, K.L. In vitro antioxidant studies in some common fruits .Intl $J$ of Pharmacy and Pharma Sci. 2011, 3(1), 60 -63.

11. Madhavi, P.; Maruthi, R.; Kamala, V.; Habibur, R.; Chinna, E.M. Evaluation of Anti-inflammatory activity of Citrullus lanatus seed oil by In-vivo and In-vitro Models. Intl Res $J$ Pharmacy and Appl Sci. 2012, 2(4), 104-108.

12. Zufarov, O.; Stefan, S.; Stanislav, S. Degumming of rapseed and sunflower oils. Acta Chimica Slovaca 2008, 1(1), 321-328.

13. Bafna, A.; Mishra, S. Antioxidant and immunomodulatory activity of the alkaloidal fraction of cissampelos pareira linn. Sci. Pharm.2010, 78, 21-31.

14. Doherty, N.S. Selective effect of immunosuppressive agents against the delayed hypersensitive response and humoral response to sheep red blood cells in mice. Agents Actions. 1981, 11, 237-242.

15. Puri, A.; Sexena, R.P.; Sexena, K.C.; Srinivasan, M.; Tandon, J.S. Immunostimulant activity of Nyctanthes arbortristis L. J Ethnopharm. 1994, 42, 31-37.

16. Greve, B.; Cassens, U.; Westerberg, C.; Ghde, W.; Sibrowski, W.; Reichelt, D. A new no-lyse, no wash flow-cytometric method for the determination of $\mathrm{CD} 4 \mathrm{~T}$ cells in blood samples. Transfus. Med. Hemother. 2003, 30, 8-13.

17. Selvaraj, R.K.; Cherian, G. Dietary n-3 fatty acids reduce the delayed hypersensitivity reaction and antibody production more than n-6 fatty acids in broiler birds. Euro J Lipid Sci and Tech. 2004, 106, 3-10.

18. Hall, J.A.; Jha, S.; Cherian, G. Dietary n-3 fatty acids decrease the leukotrienes B4 response 
ex vivo and the bovine serum albumin-induced footpad swelling index in New Hampshire hens. Canadian J Ani Sci. 2007, 87, 373-380.

19. Anderson, M.J.; Fritsche, K.L. Dietary polyunsaturated fatty acids modulate in vivo, antigen-driven CD4pT-cell proliferation in mice. J Nutr. 2004, 134, 1978-1983.

20. Mwanaidi, Y.K.; Paushali, M.; Virander, S.C. Kinetics of Humoral and Memory B Cell Response Induced by the Plasmodium falciparum 19-Kilodalton Merozoite Surface Protein 1 in Mice. Infection and Immunity 2012, 80(2), 633-642.

21. Halder, S.; Mehta, A.K.; Mediratta, P.K. Augmented humoral immune response and decreased cell mediated immunity by Aloe vera in rats, Inflammopharmacol 2012, 20, 343-346.

22. Bushra, M.; Tahira, I.; Amer, J.; Faqir, M. Effect of $\beta$-Thalassemia on haematological and biochemical profiles of female patients. Pak. J. Life and Soc. Sci. 2013, 11, 25-28.

23. Chinen, J.; Shearer, W. Secondary Immunodeficiencies, including HIV infection. J. Allergy Clin. Immunol. 2010, 125(2), 195-203.

24. Chou, CT. The anti-inflammatory effect of Tripterygium wilfordii Hook F on adjuvant-induced paw edema in rats and inflammatory mediators release. Phytotherapy Res. 1997, 11, 152-154.

25. Teresinha de Jesus, C.N.; Jair, O.; dos, S. Effect of Pathogenic Yeasts on Human Platelet Aggregation. The Braz J Infectious Dis. 2oo3, 7(6), 370-374.

26. Strom, A.; Menart, B.; Simon, M.C; Pham, M.N; Kolb, H.; Roden, M.; Pozzilli, P. Cellular interferon gamma and interleukin-13 immune reactivity in type 1, type 2 and latent autoimmune diabetes: action LADA 6. Cytokine. 2012, 58, 148-151.

27. Mayer, F.L. Wilson D, Hube B. Candida albicans pathogenicity mechanisms. Virulence 2013, 4(2), 119-128.

28. van de Veerdonk, F.L.; Mihai, G.N.; Leo, A.J.; van der Meer, J.W.M.; Bart, J.K. Novel strategies for the prevention and treatment of Candida infections: the potential of immunotherapy. FEMS Microbiol Rev. 2010, 34, 1063-1075.

29. Netea, M.G.; Gow, N.A.; Munro, C.A.; Bate, S.; Collins, C.; Ferwerda, G.; Hobson, R.P.; Bertram, G.; Hughes, H.B.; Jansen, T.; Jacobs, L.; Buurman, E.T.; Gijzen, K.; Williams, D.L.; Torensma, R. Immune sensing of Candida albicans requires cooperative recognition of mannans and glucans by lectin and Toll-like receptors. J. Clin Invest. 2oo6, 116, 1642-1650.

30. Trindade, M.C.D.; Lind, M.; Nakashima, Y.; Sun, D.; Goodman, S.B.; Schurman, D.J.; Smith, R.L. Interleukin-10 inhibits polymethylmethacrylate particle induced interleukin-6 and tumor necrosis factor- $\alpha$ release by human monocyte/macrophages in vitro. Biomaterials. 2001, 22, 2067-2073.

31. Sadeghi, S.; Wallace, F.A.; Calder, P.C. Dietary lipids modify the cytokine response to bacterial lipopolysaccharide in mice. Immunology 1999, 96, 404-410.

32. Olivares, N.; Marquina, B.; Mata-Espinoza, D.; Zatarain-Barron, Z.L.; Pinzon, C.E.; Estrada, I.; Parada, C.; Collin, M.; Rook, G.; Hernandez-Pando, R. The protective effect of immunoglobulin in murine tuberculosis is dependent on IgG glycosylation. Patho and Dis. 2013, 69, 176-183.

33. Kim, S.B.; Chang, B.Y.; Jo, Y.H.; Lee, S.H.; Han, S.B. Macrophage activating activity of pyrrole alkaloids from Morus alba fruits. J Ethnopharm. 2013, 145, 393-396.

34. Kumar, S.K.; Singh, P.; Sinha, S. Naturally produced opsonizing antibodies restrict the survival of Mycobacterium tuberculosis in human macrophages by augmenting phagosome maturation. Open Biol. 2015, 5, 150-171. 